\title{
Blocking of the sexual conditioning of differentially effective conditioned stimulus objects
}

\author{
FALIH KÖKSAL \\ Bogaziçi University, Istanbul, Turkey \\ and \\ MICHAEL DOMJAN and GABY WEISMAN \\ University of Texas, Austin, Texas
}

\begin{abstract}
The blocking phenomenon was investigated in the sexual response system of male Japanese quail. Access to a live female quail served as the unconditioned stimulus (US). The same audiovisual cue served as the pretrained stimulus in all of the experiments. Following asymptotic conditioning of the audiovisual cue, a second conditioned stimulus (CS2) was added. In Experiment 1, CS2 was a rectangular wood block that had little or no resemblance to a female quail and could not support copulatory behavior. In Experiment 2, CS2 was a terrycloth object that had no quail parts but could support copulatory behavior, and, in Experiment 3, CS2 was a terrycloth object that had a taxidermically prepared head of a female quail added. The terrycloth-only object supported more rapid conditioning than did the wood block, but the blocking effect was obtained with both kinds of stimuli. Approach responding to the terrycloth + head object required pairing it with copulatory opportunity, and the terrycloth + head object supported at least as rapid conditioning as did the terrycloth-only object. However, responding to the terrycloth + head object was not blocked by the pretrained audiovisual cue. These results indicate that the blocking effect occurs in sexual conditioning even with stimulus objects that can support copulation. However, the addition of species-typical head cues to an object makes that object such a powerful stimulus that conditioned approach responding to it cannot be blocked by a previously conditioned arbitrary audiovisual cue.
\end{abstract}

One of the cornerstones of contemporary investigations and interpretations of Pavlovian conditioning is the blocking effect, which was originally demonstrated by Kamin (1969) in a standard fear conditioning preparation with rat subjects. In the first phase of the blocking experiment, the rats received a noise conditioned stimulus (CS) paired with a shock unconditioned stimulus (US). During the next phase, a light CS was added to the noise $C S$, and the noise-light compound was paired with the shock. The basic finding was that the presence of the previously conditioned noise blocked the conditioning of the light stimulus. If the noise was omitted on the light-shock trials, no blocking occurred. Blocking also did not occur if the light was presented with a noise stimulus that had not been previously conditioned. The blocking effect contributed to fundamental changes in theories of Pavlovian condi-

The research was supported by Grants INT-9122748 from the National Science Foundation and MH39940 from the National Institute of Mental Health. The experiments were conducted while F. Köksal was a visiting scientist at the University of Texas. Correspondence should be addressed to F. Köksal, Department of Psychology, Bogaziçi University, 80815 Bebek, Istanbul, Turkey, or M. Domjan, Department of Psychology, University of Texas, Austin, TX 78712. tioning because it illustrated that contiguity is not sufficient for the acquisition of associations and suggested that more complex information processing variables are also important in conditioning.

Blocking is a well-established phenomenon. However, most experiments on blocking have been conducted with food or shock reinforcement, and, with few exceptions, the CSs were selected arbitrarily on the basis of procedural convenience. The purpose of the present experiments was to explore the blocking effect in a novel conditioning preparation-namely, the sexual conditioning of male Japanese quail. In addition, the nature of the added CS was investigated. In successive experiments, the added CS was made more quail-like and more effective in supporting copulatory behavior.

Studies of selective associations have demonstrated that the relevance of a CS to a US can significantly influence the course of associative learning (see Domjan, 1983, for a review). In particular, "relevant" CSs and USs become associated much more quickly than do arbitrary combinations of CSs and USs. Stimulus relevance may also influence the course of the blocking effect. The conditioning of stimuli that are more relevant to the US employed in a blocking procedure may be less easily blocked by the presence of a previously conditioned CS. 
Evidence of the role of stimulus relevance in the blocking effect was obtained by LoLordo, Jacobs, and Foree (1982). In earlier research, Foree and LoLordo (1973) found that, in pigeons, auditory cues are more effective than visual cues in avoidance conditioning, whereas visual cues are more effective than auditory cues in conditioning reinforced with food. LoLordo et al. extended these findings to a blocking design. They found that, in a food-conditioning procedure, the presence of a previously conditioned auditory CS did not block the acquisition of discriminative control by an added visual cue. Conversely, in an avoidanceconditioning experiment, the presence of a previously conditioned visual CS did not block acquisition of control by an added auditory cue. In a related appetitive-conditioning experiment with rats, Feldman (1975) found that the degree of blocking is influenced by the intensity of the added stimulus. Increasing the intensity of the added CS can attenuate the blocking effect.

Male Japanese quail (Cotumix coturnix japonica) served as subjects in the present experiments. When kept on an appropriate photoperiod (16:8-h light:dark cycle), the quail learn to approach and stay near a conditioned stimulus that is paired with access to a female (e.g., Domjan, Lyons, North, \& Bruell, 1986; Domjan, O'Vary, \& Greene, 1988; Holloway \& Domjan, 1993). This conditioned approach behavior is under the control of Pavlovian rather than instrumental contingencies (Crawford \& Domjan, 1993). The blocking effect was evaluated in the conditioned sexual approach paradigm.

The same audiovisual cue served as the pretrained stimulus in all of the experiments. Following asymptotic conditioning of the audiovisual cue, a second CS was added (CS2). CS2 was always a three-dimensional (3-D) object. In Experiment 1, CS2 was a rectangular wood block that had little or no resemblance to a female quail and could not support copulatory behavior. In Experiment 2, CS2 was a terrycloth object that had no quail parts but could support copulatory behavior (see Domjan, Huber-McDonald, \& Holloway, 1992). Finally, in Experiment 3, CS2 was a terrycloth object that had a taxidermically prepared head of a female quail added. We were interested in determining how the blocking effect would be influenced by whether or not CS2 could support copulatory behavior and whether or not it had quail features.

\section{EXPERIMENT 1}

Three groups of subjects were tested in Experiment 1: blocking, Control 1 , and Control 2 . The opportunity to copulate with a female quail served as the US. The experiment consisted of two phases. In Phase 1, the subjects in the blocking group received exposure to an audiovisual stimulus (CS1) paired with copulatory opportunity on each of 15 conditioning trials, which resulted in asymptotic responding. CS1 was then presented together with a wood block (CS2) and paired with copulatory opportunity. Periodically, CS2 was presented alone and unreinforced to assess responding to it.
The subjects in Control Group 1 also received CS1 and US presentations in Phase 1 of the experiment, but in an unpaired manner. In Phase 2, their treatment was identical to that of the birds in the blocking group. Control Group 1 was included to evaluate possible nonassociative effects of CS1 and US presentations in Phase 1. The subjects in Control Group 2 received neither CS1 nor US presentations in Phase 1 of the experiment but received the same pairings of the CS1-CS2 compound with copulatory opportunity in Phase 2, as did all of the other subjects.

\section{Method}

Subjects. Eighteen 3-month-old sexually naive male Japanese quail (Coturnix coturnix japonica), selected from the breeding colony maintained at the University of Texas at Austin, served as subjects. They were randomly assigned to three groups. One subject in Control Group 2 was dropped in Phase 2 of the experiment due to its excessive fear response to presentations of CS2.

Six 3-month-old female Japanese quail selected from the same colony were used to provide copulatory opportunity.

Apparatus. Six test cages, 121 (wide) $\times 71$ (high) $\times 121 \mathrm{~cm}$ (deep), adjacent to each other, were used. The floor and the front were made of wire mesh, and the remaining walls were made of 1.5-cm plywood (see Figure 1). The front walls were hinged to permit servicing the chambers. Food and water were provided near the front. Cages for females, 29 (wide) $\times 35$ (high) $\times 60 \mathrm{~cm}$ (deep), were attached to the sides of the males' cages, centered along one side wall. A vertically sliding door, 18 (wide) $\times 20 \mathrm{~cm}$ (high), separated each male's cage from its adjacent female's cage. CS1 was an audiovisual stimulus created by a buzzer (Archer 273-055) and a flashing green light ( 12 volts and $95 \mathrm{~mA}$ ) located on the top of each door. Fifteen centimeters away from the door, a wooden block, 1.5 (wide) $\times 10$ (high) $\times 15 \mathrm{~cm}$ (deep), was suspended from the ceiling on a pulley. Lowering the block to the floor on a guide wire on each end served as CS2. A rectangular area, 43 (wide) $\times 45 \mathrm{~cm}$ (deep), was marked on the floor of the experimental chamber around the source of the audiovisual cue. Time spent in this area during presentations of the CS was used as a measure of approach to the CS.

Procedure. The 18 subjects were assigned to three squads $-\mathrm{A}$, $\mathrm{B}$, and $\mathrm{C}-$ and 2 birds in each squad were randomly assigned to each of the three groups. Food and water were available ad lib. Each squad was housed in the experimental chambers every 3rd day. While the subjects of one squad were in the test cages, the subjects of the other two squads were housed in the colony cages.

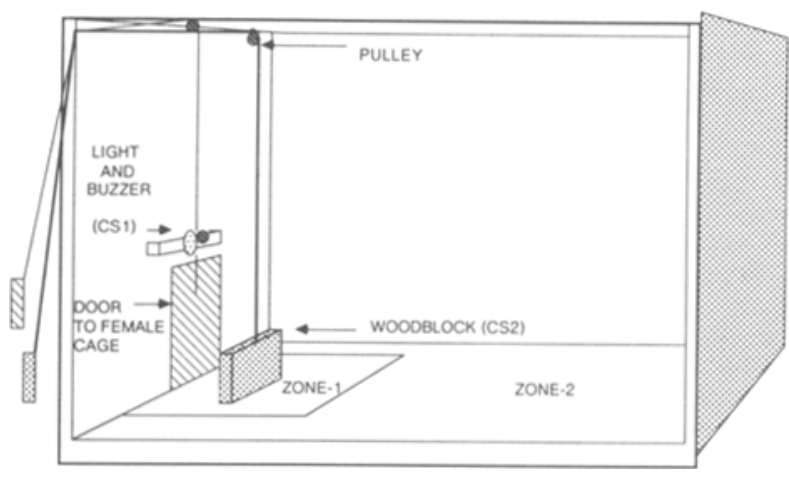

Figure 1. Diagram of the test chambers used in Experiment 1. The subject was considered to be near the CS when it had both legs in Zone 1. 
The birds were exchanged around noon each day, when those that had been in the test cages were placed in the colony cages and one of the other squads was brought into the test cages. If, for example, Squad A had spent the night in the test cages, it was moved to the colony cages around noon the next day, and Squad B was placed in the test cages. This squad was kept in the test cages until noon of the following day, when Squad $\mathrm{C}$ was brought into the test cages and Squad B was moved back to the colony cages. This procedure was started 20 days before any experimental manipulations were performed to habituate the birds to the test cages and to the handling. During the habituation period, the subjects also received access to a female quail twice for $5 \mathrm{~min}$. On these occasions, the female was released into the test cage through the front service door. Experimental treatments were conducted each day in the late morning and in the midafternoon. Thus, each day, the birds of two squads were exposed to the conditioning procedure. Each subject received one trial on each of 2 successive days and rested in the colony cage on Day 3.

Phase 1 of the experiment started on Day 21. The experimenter placed a female through the front service door into the test cage of each subject in Control Group 1. The female was removed $5 \mathrm{~min}$ later. Following a 25-35-min interval, CS1 (buzzer + light) was presented for $30 \mathrm{sec}$ to the blocking and Control 1 groups. Immediately after the termination of CSI, the US (access to a female quail) was presented only to the blocking group by opening the door to the females' cages. For the subjects in Control Group 1, the females were removed from their cages prior to the beginning of the CS1 presentation, and opening the females' doors did not result in access to a female bird. The subjects in Control Group 2 received neither CS1 nor US presentations in Phase 1; the experimenter opened the door to the females' cages for $5 \mathrm{~min}$ on each trial, but the females were removed prior to the beginning of the trials.

Each day, the order of running the subjects was randomized across cages. Forty minutes after the completion of each morning trial, the animals were moved to their colony cages, and the next squad was brought into the test cages. The new squad was allowed to rest in the test cages for about $40 \mathrm{~min}$ before the beginning of their trial. The rest of the procedures were the same as for the previous squad. Phase 1 took 22 days (15 trials for each bird). The subjects' responses to CS1 were recorded on videotape on Trials 5, 10, and 15 .

In Phase 2, all groups received the identical procedure. CS1 and CS2 were presented for $30 \mathrm{sec}$, followed by access to a female quail for $5 \mathrm{~min}$. The audiovisual cue was turned on as the wood block began to be lowered and was turned off as the wood block began to be raised back up. All groups received four conditioning trials in Phase 2, followed by a 30-sec test trial in which CS2 was presented alone unreinforced. Four more compound conditioning trials were then conducted, followed by three 30-sec CS2-alone test trials. A 2-day interval intervened between each of the last three test trials. All test trials, as well as a 30 -sec period immediately before each test, were recorded on videotape, and time spent near the CS was subsequently measured from the video records by an observer. Interobserver reliability correlations for this response measure have been found to be near .99 (Domjan \& Ravert, 1991).

\section{Results}

Time spent in the CS zone $30 \mathrm{sec}$ before (pre-CS) and 30 sec during presentations of CSI in Phase 1 of the experiment was observed for the blocking and Control 1 groups on Training Trials 5, 10, and 15. Starting from Trial 5, the blocking group, which received pairings of CSI and the US, spent most of its time near the CS during the audiovisual cue. Mean times in the CS zone for the pre-CS and CS periods were 1 and 20.3, 0.5 and 23.3, and 1.8 and $21.1 \mathrm{sec}$ for Trials 5,10 , and 15, respectively. In contrast, the subjects in Control Group 1 , which received unpaired presentations of CS1 and the US, spent equally little time in the CS zone during the pre-CS and CS1 periods. Their means for the pre-CS and CS periods were 2 and $0.8,0.8$ and 0.3 , and 1.5 and $0.8 \mathrm{sec}$ for Trials 5,10 , and 15 , respectively. These results indicate that, for the blocking subjects, the CS1-US association was well-established in Phase 1, whereas no such association developed for the subjects in Control Group 1. Control Group 3 subjects received neither CS1 nor the US in Phase 1 of the experiment.

The birds spent very little time in the CS zone during the pre-CS periods of the CS2-alone test trials in Phase 2 of the experiment. The mean pre-CS times for the blocking, Control 1, and Control 2 groups were 2.4, 1.4, and $3.2 \mathrm{sec}$, respectively, for the CS2 test trials. The pre-CS times for each subject were subtracted from the time they spent in the CS zone during the CS2 test trials, and these difference scores are summarized in Figure 2.

The subjects in the blocking group showed much less approach to CS2 than did the subjects in the two control groups, which showed almost identical responding. In contrast to the control groups, which showed strong approach responding after just eight compound conditioning trials, the subjects in the blocking group spent means of less than $10 \mathrm{sec}$ near CS2 on each 30-sec test trial. A repeated measures analysis of variance (ANOVA) was calculated comparing time spent near CS2 during four test trials across two control groups. This analysis showed no significant effects either for group or the group $\times$ test trials interaction $(F \mathrm{~s}<1)$. Therefore, the data for the two control groups were combined and compared with the data for the blocking group. The results of a repeated measures ANOVA comparing the blocking and the control groups across the four test trials showed a significant group $\times$ trials interaction $[F(3,45)=3.0, p<.05]$. Subsequent analyses indicated that responding in the control groups increased significantly across CS2 test trials

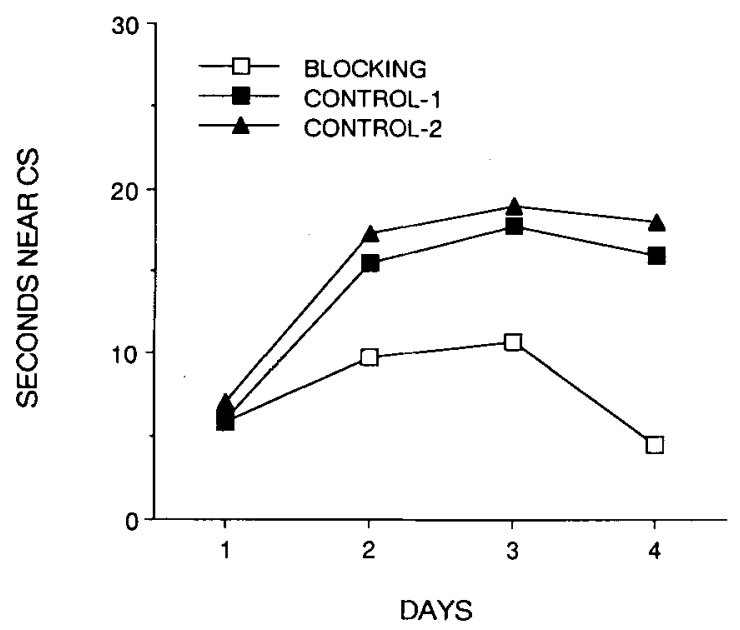

Figure 2. Mean time spent near CS2 (minus pre-CS scores) during the test trials for the blocking, Control 1, and Control 2 groups in Experiment 1. (CS2 was a wood block.) 
$[F(3,30)=15.89, p<.01]$. In contrast, responding in the blocking group did not change significantly as a function of trials $(F<1.0)$.

\section{Discussion}

Conditioned sexual approach responding to the audiovisual stimulus developed rapidly in the blocking group. The subjects achieved asymptotic responding by Trial 5 , spending a bit more than $20 \mathrm{sec}$ of the 30 -sec CS period in the CS zone. In contrast, little responding (less than $1 \mathrm{sec}$ on average) occurred in Control Group 1, which received unpaired presentations of the audiovisual stimulus and copulatory opportunity. Thus, the conditioned approach responding that developed to the audiovisual cue in the blocking group was an associative effect. These findings confirm other evidence of the associative basis of conditioned approach responding in the sexual conditioning of male Japanese quail (Domjan et al., 1986; Domjan et al., 1988; Holloway \& Domjan, 1993).

In the control groups, conditioned approach responding developed rapidly to the wood block that was introduced in Phase 2 of the experiment. These subjects spent nearly $20 \mathrm{sec}$ near CS2 after eight compound conditioning trials. In contrast, only minimal approach responding to CS2 developed in the blocking group.

The difference between the blocking and Control 1 groups can be explained in terms of overshadowing of CS2 by CS1 (Carr, 1974), superconditioning (Rescorla, 1971), or blocking. Results of various studies have shown that exposure to uncorrelated presentations of a CS and US retards subsequent conditioning with these stimuli (Baker \& Mackintosh, 1977; Gamzu \& Williams, 1973; Tomie, Murphy, Fath, \& Jackson, 1980). Such an effect, commonly referred to as "learned irrelevance," is assumed to be caused by reduced attention to the CS due to the previous uncorrelated CS and US presentations (Baker \& Mackinosh, 1977). Although the mechanisms of learned irrelevance remain to be clarified, the phenomenon is well-established (Mackintosh, 1973; Matzel, Schachtman, \& Miller, 1988). In a study related to these findings, Carr (1974) reported that exposure to random presentations of CS and US also reduces the CS's potential to overshadow another stimulus when the two stimuli are presented in compound and paired with the same US. Thus, the higher level of conditioned responding to CS2 in Control Group 1 than in the blocking group may have been caused by CS1's reduced overshadowing potential in Control Group 1.

Alternatively, it is possible to argue that unpaired presentations of CS1 and the US might have established CS1 as a conditioned inhibitor. When an inhibitor is presented in compound with a novel stimulus and paired with the US employed in the inhibitory conditioning, it leads to faster conditioning of the added stimulus. This effect is called "superconditioning" (Rescorla, 1971).

The similar performance of Control Group 1 and Control Group 2 suggests that neither learned irrelevance nor superconditioning was involved in the present study. Following unpaired US/CS1 presentations, if the overshad- owing power of CS1 had been reduced, or if CS1 had become a conditioned inhibitor, conditioning of CS2 should have been stronger in Control Group 1 than in Control Group 2. Contrary to this prediction, the results of the present study indicated that the two groups were not significantly different from each other. In fact, Control Group 2 responded slightly more vigorously to CS2 than did Control Group 1.

The similar results of Control Group 1 and Control Group 2 suggest that the retarded acquisition of CS2 in the blocking group occurred because of a blocking effect. Therefore, the present results demonstrate, for the first time, that a previously conditioned stimulus can block the conditioning of a novel stimulus in a sexual conditioning paradigm.

\section{EXPERIMENT 2}

In Experiment 2, we began to explore features of an added stimulus that might make it resistant to blocking by a previously conditioned arbitrary cue. One possibility is that blocking is obtained in sexual conditioning only if the added conditioned stimulus cannot support copulatory behavior. Copulation in male quail consists of the male grabbing the back of the female's head or neck, mounting her back, and then bringing its cloaca in contact with the cloaca of the female in a series of thrusting cloacal contact movements. The wood block that served as CS2 in Experiment 1 could not support these grab, mount, and cloacal contact responses because of its texture and shape.

A 3-D object also served as CS2 in Experiment 2. However, unlike the wood block that was used in Experiment 1, CS2 in Experiment 2 could support copulatory behavior because it was made of light blue terrycloth and filled with soft polyester fiber. The object consisted of a vertical cylinder that male quail could grab and a pad that they could mount and on which they could make cloacal thrusts (see Object 6 in Figure 1 of Domjan et al., 1992). With the exception of the new object that served as CS2, the procedures for Experiment 2 were similar to those of Experiment 1.

\section{Method}

Subjects. Twelve 3-month-old sexually naive male Japanese quail (Coturnix coturnix japonica) selected from the breeding colony maintained at the University of Texas at Austin served as subjects. They were randomly assigned to three groups. Six 3-month-old female Japanese quail selected from the same colony were used to provide copulatory opportunity.

Apparatus. The same six experimental chambers were used as were used in Experiment 1, and CS1 was the same audiovisual cue. CS2 was a blue terrycloth object filled with soft polyester fiber. It consisted of an 8-cm-tall vertical section (about $2.5 \mathrm{~cm}$ in diameter), positioned in front of a 5.0-cm-high, $5.5-\mathrm{cm}$-wide, and 11.5-cm-long mounting pad. When not in use, the terrycloth object was hidden under a wooden hood $(14 \mathrm{~cm}$ wide, $8.9 \mathrm{~cm}$ high, and $14 \mathrm{~cm}$ deep). Presentation of the terrycloth object was achieved by raising the covering hood with a string passed over a pulley.

Procedure. The 12 subjects were assigned to two squads, $A$ and $B$, and 2 birds in each squad were randomly assigned to each of 
the three groups. Food and water were available ad lib. Each squad was housed in the experimental chambers in the morning or afternoon of each day. While the subjects of one squad were in the test cages, the subjects of the other squad were housed in the colony cages. The birds were exchanged around noon each day. This alternate-housing procedure was started 7 days before any experimental manipulations. During the habituation period, the subjects also received access to a female quail once for $5 \mathrm{~min}$. The female was released into the test cages through the front service door on this occasion. Experimental treatments were conducted each day in the late morning and in the midafternoon.

Phase 1 of the experiment started on Day 8. The experimental procedures were identical to those of Experiment 1 in all respects except that the terrycloth object served as CS2, and, during the compound conditioning trials, CS2 remained visible during the US period when the subjects had access to a female quail.

\section{Results and Discussion}

Conditioning of the audiovisual stimulus proceeded as in Experiment 1. Time spent in the CS zone $30 \mathrm{sec}$ before (pre-CS) and $30 \mathrm{sec}$ during presentations of CS1 in Phase 1 of the experiment was observed for the blocking and Control 1 groups on Training Trials 5, 10, and 15. Starting from Trial 5, the blocking group, which received pairings of CS1 and the US, spent substantial periods of time near the CS during the audiovisual cue. Its mean times in the CS zone for the pre-CS and CS periods were 3.2 and 11.8, 10 and 19.7, and 6.5 and $14.8 \mathrm{sec}$ for Trials 5,10 , and 15 , respectively. Control Group 1 subjects, which received unpaired presentations of CS1 and the US, spent equally little time in the CS zone during the pre-CS and CS1 periods. Their means for the pre-CS and CS periods were 5.5 and $0.5,1.0$ and 0 , and 6.0 and $2.0 \mathrm{sec}$ for Trials 5,10 , and 15, respectively. These results indicate that, for the blocking subjects, the CS1-US association was well-established in Phase 1, whereas no such association developed for the subjects of Control Group 1. (Control Group 2 subjects received neither CS1 nor the US in Phase 1 of the experiment.)

As in Experiment 1, the subjects spent very little time in the CS zone during the pre-CS periods of the CS2-alone test trials in Phase 2 of the experiment. The mean preCS times for the blocking, Control 1, and Control 2 groups were $3.7,1.7$, and $2.5 \mathrm{sec}$, respectively, for the CS2 test trials. The pre-CS times for each subject were subtracted from the time they spent in the CS zone during the CS2 test trials, and these difference scores are summarized in Figure 3.

Approach to the terrycloth object developed very rapidly in the control groups, so much so that asymptotic levels of responding were evident by the first test trial, conducted after four compound conditioning trials in Phase 2 of the experiment. Thus, the terrycloth object appears to have been a much more effective conditioned stimulus than was the wood block that was used in Experiment 1 (cf. Figure 2). This increased effectiveness of CS2 may have been related to its softness or shape, which permitted copulatory responding (see Domjan et al., 1992). However, only one of the subjects (in Control Group 2) was ever observed to direct any copulatory responses (grab, mount, or cloacal contact) toward the terrycloth object.

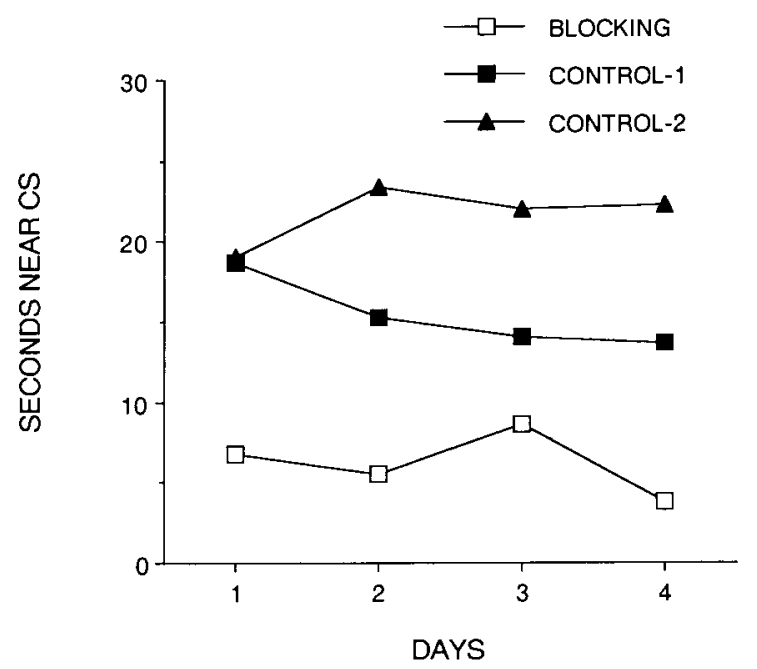

Figure 3. Mean time spent near CS2 (minus pre-CS scores) during the test trials for the blocking, Control 1, and Control 2 groups in Experiment 2. (CS2 was a terrycloth object.)

In contrast to the control groups, which showed strong and asymptotic approach responding after just four compound conditioning trials, the subjects in the blocking group spent means of less than $10 \mathrm{sec}$ near CS2 on each test trial. A repeated measures ANOVA was calculated comparing the time spent near CS2 during four test trials across two control groups. The results showed no significant effects either for group or the group $\times$ test-trials interaction $(F \mathrm{~S}<1)$. Therefore, the data for the two control groups were combined and compared with the data for the blocking group. The results of a repeated measures ANOVA comparing the blocking and the control groups across the four test trials showed a significant group effect $[F(1,30)=7.06, p<.05]$. The groups $\times$ trials interaction was not significant $(F<1.0)$. This outcome indicates that the control groups spent significantly more time near CS2 across the four test trials than did the blocking group, and this effect did not change after the first test trial with CS2.

The results of Experiment 2 demonstrate that blocking occurs in sexual conditioning even if the added conditioned stimulus can support both very rapid acquisition and components of copulatory responding. These results extend the generality of the blocking effect.

\section{EXPERIMENT 3A}

In Experiment 3, we examined the blocking effect with a terrycloth object that was made more salient by the addition of a taxidermically prepared head to the vertical portion of the object. In an effort to minimize unconditioned responding to this stimulus object, no neck feathers were included with the head (cf. Domjan, Greene, \& North, 1989; Domjan \& Nash, 1988).

Experiment 3A was conducted to determine the extent to which approach and copulatory responses to the terry- 
cloth + head object reflected associative processes. Two groups of subjects were compared. For one group, the terrycloth + head object was presented paired with copulatory opportunity. For another group, the stimulus object and copulatory opportunity were presented unpaired. After every second conditioning day, a nonreinforced test trial was conducted in which the terrycloth + head object was presented alone to both groups. This permitted assessment of responding to the CS object when the two groups were equally sexually deprived.

\section{Method}

Subjects. Twelve 3-month-old sexually naive male Japanese quail (Coturnix coturnix japonica) served as subjects. They were randomly assigned to two groups of 6 subjects each. Six 3-month-old female Japanese quail were used to provide copulatory opportunity.

Apparatus. The same six experimental chambers that were used in Experiments 1 and 2 also served in Experiment 3A. The CS object was similar to the terrycloth object used in Experiment 2, except that a taxidermically prepared female quail head was glued on top of the vertical section of the terrycloth object. The head section of the terrycloth object was stuffed somewhat loosely (as in Experiment 2) so that the head could move if the subject grabbed it. Stimulus presentations were conducted as in Experiment 2.

Procedure. The procedures were similar to Phase 1 of Experiment 2 in all unspecified respects. The terrycloth + head object was used as the CS. The subjects were randomly assigned to one of two groups. For the paired group, each conditioning trial consisted of exposure to the CS starting $30 \mathrm{sec}$ before the release of a live female quail for $5 \mathrm{~min}$, at which point both the CS and the female were removed. The unpaired group was exposed to the CS object and the US in the same unpaired manner as was Control Group 1 in Phase 1 of Experiment 2. After every second conditioning day, an unreinforced test trial with the terrycloth + head object was conducted for all subjects. This sequence of two reinforced trials and one test trial was repeated three times. The CS object was presented for $30 \mathrm{sec}$ on each test trial. The subjects were recorded on videotape for $30 \mathrm{sec}$ before each CS presentation and during the first $30 \mathrm{sec}$ of stimulus exposure on each trial.

\section{Results and Discussion}

Six of the 12 subjects withdrew from the CS area when the terrycloth + head object was presented the first time. The mean time spent in the CS area during the pre-CS period of Trial 1 was $1.92 \mathrm{sec}$, whereas none of the subjects spent any time in the CS area when the terrycloth + head object was presented. This difference was significant $[F(1,11)=7.71, p<.05]$ and indicates that the terrycloth + head object did not elicit approach (or copulatory) behavior unconditionally. In fact, the initial response to the object was withdrawal.

The pre-CS times for each subject were subtracted from the time they spent in the CS zone during CS presentations, and these difference scores are summarized in Figure 4. The unpaired group increased its time near the CS from Trial 1 to Trial 2 but not thereafter. In contrast, the paired group showed a much larger and persistent increase in responding across trials. The results of a repeated measures ANOVA comparing the paired and unpaired groups across all trials showed a significant effect of groups $[F(1,10)=5.15, p<.05]$ and a significant group $\times$ trials interaction $[F(8,80)=3.85, p<.01]$. Subsequent analyses of the data excluding Trial 1 revealed a signifi-

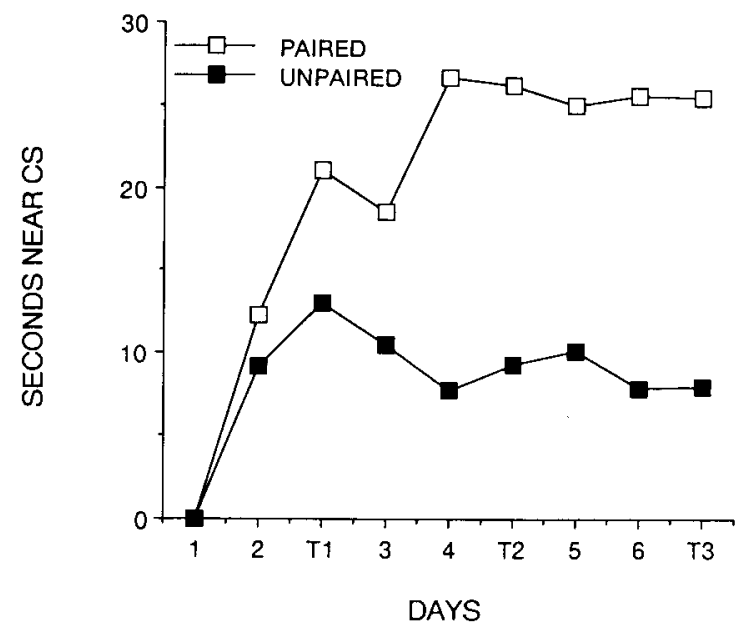

Figure 4. Mean time spent near a terrycloth + head CS (minus pre-CS scores) in Experiment 3A. (For the paired group, exposure to the CS was paired with copulatory opportunity. For the unpaired group, copulatory opportunity occurred before exposure to the CS. A nonreinforced test trial was conducted after each of Trials 2, 4, and 6.)

cant effect of trials for the paired group $[F(1,35)=5.04$, $p<.01]$ but not for the unpaired group $(F<1.0)$.

In addition to measuring approach to the CS object, the frequency of grab, mount, and cloacal contact responses to the terrycloth + head object was measured for each test session. The mean and standard error of the mean of these measures are presented in Table 1 . The subjects in the paired group showed increased levels of copulation with the terrycloth + head model as the experiment progressed. By the last test trial, all of the subjects in the paired group made at least one grab response to the terrycloth + head model. In contrast, only 2 of the subjects in the unpaired group ever showed any copulatory responses toward the CS object.

Separate ANOVAs were conducted for each copulatory response measure (grab, mount, and cloacal contact movement). The increased responding in the paired group across trials, contrasted with constant and lower levels of responding in the unpaired group, resulted in signifi-

Table 1

Mean Frequency $(M F)$ and Standard Error of the Mean (SEM) of Copulatory Responses Observed During the Test Trials of Experiment $3 \mathrm{~A}$

\begin{tabular}{|c|c|c|c|c|c|c|}
\hline \multirow[b]{2}{*}{ Trial } & \multicolumn{2}{|c|}{ Grab } & \multicolumn{2}{|c|}{ Mount } & \multicolumn{2}{|c|}{ Cloacal Contact } \\
\hline & $M F$ & $S E M$ & $M F$ & $S E M$ & $M F$ & SEM \\
\hline \multicolumn{7}{|c|}{ Group Paired } \\
\hline $\begin{array}{l}1 \\
2 \\
3\end{array}$ & $\begin{array}{l}1.5 \\
2.8 \\
4.3\end{array}$ & $\begin{array}{l}0.56 \\
0.91 \\
0.80\end{array}$ & $\begin{array}{l}1.7 \\
3.0 \\
4.2\end{array}$ & $\begin{array}{l}0.84 \\
0.97 \\
1.14\end{array}$ & $\begin{array}{l}1.3 \\
2.7 \\
3.5\end{array}$ & $\begin{array}{l}0.88 \\
0.96 \\
1.15\end{array}$ \\
\hline \multicolumn{7}{|c|}{ Group Unpaired } \\
\hline $\begin{array}{l}1 \\
2 \\
3\end{array}$ & $\begin{array}{l}1.3 \\
1.3 \\
0.5\end{array}$ & $\begin{array}{l}0.84 \\
0.99 \\
0.34\end{array}$ & $\begin{array}{l}1.8 \\
1.3 \\
1.5\end{array}$ & $\begin{array}{l}1.33 \\
0.99 \\
1.15\end{array}$ & $\begin{array}{l}1.2 \\
1.5 \\
1.5\end{array}$ & $\begin{array}{l}1.17 \\
1.15 \\
1.15\end{array}$ \\
\hline
\end{tabular}


cant groups $\times$ trials interaction for the grab and mount response measures $[F \mathrm{~s}(2,20)=4.87$ and 3.74 , respectively, $p \mathrm{~s}<.05]$.

The present results provide little evidence that the terrycloth + head object elicited much behavior unconditionally. However, pairings with copulatory opportunity resulted in rapid acquisition of both high levels of approach to the terrycloth + head object and copulation with it. In contrast, the unpaired procedure produced little responding. The modest degree of approach and copulatory behavior evident in the unpaired group reflected the behavior of just 2 of the 6 subjects. The remaining birds in the unpaired group showed much less approach and no copulatory behavior.

\section{EXPERIMENT 3B}

The results of Experiment 3A indicated that although responding to the terrycloth + head object develops rapidly, the approach and copulatory behavior directed toward the object reflects primarily associative processes. Experiment 3B was conducted to determine whether sexual conditioning of the terrycloth + head object could be blocked by a previously conditioned audiovisual cue. The procedures were similar to those of Experiments 1 and 2 , with two exceptions. First, the terrycloth + head object used in Experiment 3A served as CS2. Second, as in Experiment 3A, a nonreinforced test trial with CS2 was conducted after every two reinforced trials in the compound conditioning phase of the experiment. More frequent testing was conducted in Experiment $3 \mathrm{~B}$ than in Experiments 1 or 2 because responding to the terrycloth + head object developed very rapidly.

\section{Method}

Subjects. Twelve 3-month-old sexually naive male Japanese quail (Coturnix coturnix japonica) served as subjects. They were randomly assigned to three groups of 4 subjects each. Six 3-month-old female Japanese quail were used to provide copulatory opportunity.

Apparatus. The same six experimental chambers that were used in Experiments 1 and 2 also were used in Experiment 3B. CS1 was the audiovisual cue that was used in Experiments 1 and 2. CS2 was the terrycloth + head object used in Experiment $3 \mathrm{~A}$.

Procedure. The procedure was identical to that of Experiment 2 in all unspecified respects. Following every second compound conditioning trial in Phase 2, a test trial was conducted in which CS2 was presented alone. This sequence of two reinforced compound trials and one CS2 test trial was repeated four times. The data for one of the subjects in Control Group 2 were discarded because this subject failed to copulate with the live female that was presented on the conditioning trials.

\section{Results and Discussion}

Conditioning of the audiovisual stimulus proceeded as in Experiments 1 and 2. Time spent in the CS zone $30 \mathrm{sec}$ before and $30 \mathrm{sec}$ during presentations of CS1 in Phase 1 of the experiment was observed for the blocking and Control 1 groups on Training Trials 5, 10, and 15. Starting from Trial 5, the blocking group, which received pairings of CS1 and the US, spent most of its time near the CS during the stimulus presentation. Its mean times in the CS zone for the pre-CS and CS periods were 0.5 and $16.7,1.5$ and 23.5, and 0 and $22 \mathrm{sec}$ for Trials 5, 10, and 15 , respectively. Control Group 1 subjects, which received unpaired presentations of CS1 and the US, spent equally little time in the CS zone during the pre-CS and CS periods. Their mean times for the pre-CS and CS periods were 0 and 0,0 and 6 , and 0 and $0.5 \mathrm{sec}$ for Trials 5,10 , and 15 , respectively.

As in Experiment 1, the subjects spent very little time in the CS zone during the pre-CS periods of the CS2-alone test trials in Phase 2 of the experiment. The mean preCS times for the blocking, Control 1, and Control 2 groups were $.6,0$, and $3.7 \mathrm{sec}$ for the CS2 test trials. The pre-CS times for each subject were subtracted from the time they spent in the CS zone during the CS2 test trials, and these difference scores are summarized in Figure 5.

Approach to the terrycloth + head object developed very rapidly in the control groups, so much so that asymptotic levels of responding were evident by Test Trial 1 , conducted after two compound conditioning trials in Phase 2 of the experiment.

In contrast to Experiment 2, both control and blocking groups showed strong approach responding after just two compound conditioning trials. A repeated measures ANOVA was calculated comparing time spent near CS2 during four test trials across two control groups. The results showed no significant effects either for group $(F<1)$ or for the group $\times$ test trials interaction $(F<1)$. Therefore, the data for the two control groups were combined and compared with the data for the blocking group. The results of a repeated measures ANOVA comparing the blocking and the control groups across the four test trials showed no significant group effect $(F<1)$ or group $\times$ test trials interaction $(F<1)$. These findings indicate that the blocking subjects spent as much time near CS2 as did the control groups.

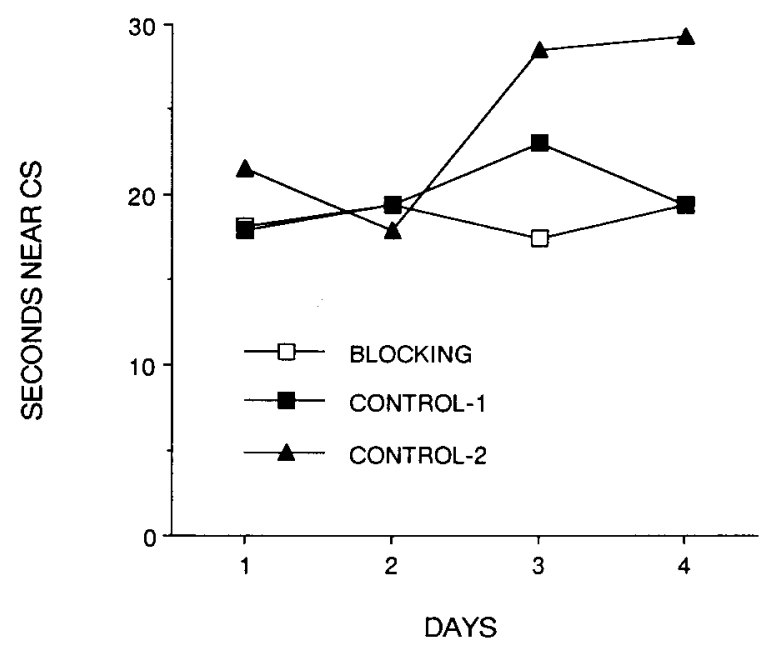

Figure 5. Mean time spent near CS2 (minus pre-CS scores) during the test trials for the blocking, Control 1, and Control 2 groups in Experiment 3B. (CS2 was a terrycloth object with a taxidermically prepared female quail head attached.) 
The subjects in Experiment 3B showed less copulation with the terrycloth + head object during the CS2 test trials than did the subjects in Experiment 3A. The mean and standard error of the mean of the overall frequency of grab, mount, and cloacal contact responses during all of the CS2 test trials were 0.7 and $0.12,0.9$ and 0.22 , and 1.2 and 0.29 , respectively. Separate ANOVAs were computed for each response measure. These analyses failed to show any significant effects for the grab and mount responses. There were significant effects of trials $[F(3,24)$ $=6.4, p<.01]$ and a groups $\times$ trials interaction $[F(6,24)=3.4, p<.05]$ for the cloacal contact response. However, these effects reflected a difference between the control groups rather than a blocking effect. None of the subjects in Control Group 1 made any cloacal contact responses to the terrycloth + head object. In contrast, all of the subjects in Control Group 2 made cloacal contact responses by Test Trial 4 . (Among the 4 subjects in the blocking group, two made cloacal contact responses by the last CS2 test trial.)

The results of Experiment 3B demonstrate that conditioning of a stimulus is not blocked by a previously conditioned cue if the new conditioned stimulus has added species-typical features. The terrycloth-only object was rapidly conditioned in the control groups of Experiment 2, but this conditioning was significantly blocked by a previously conditioned audiovisual cue. The addition of a female quail head to the terrycloth object made that object resistant to the blocking effect in Experiment 3B. The added female head cues may have increased the salience, intensity, or "relevance"' of the stimulus object. Thus, the present results are consistent with the findings of LoLordo et al. (1982) and Feldman (1975) indicating that blocking is less likely to occur with more intense or more relevant conditioned stimuli.

In Experiment 3, cues of a female quail's head were the species-typical cues that were added to the terrycloth object. Domjan and Nash (1988) found that cues of a female's head are especially salient for social behavior in quail. However, subsequent research (Crawford \& Akins, 1993) has indicated that the shape and plumage of a female quail's body (without the head or neck) can also stimulate male copulatory behavior. We do not know whether plumage other than from a female's head can also create resistance to blocking if added to an arbitrary terrycloth object.

\section{GENERAL DISCUSSION}

The purpose of the present experiments was to investigate whether the blocking effect occurs in sexual conditioning and to determine whether the degree of blocking depends on the nature of the blocked CS. The results of Experiments 1 and 2 showed that blocking in the sexual conditioning of male Japanese quail is a rather robust phenomenon. An arbitrary audiovisual CS was effective in blocking the conditioning of both a wood block and a terrycloth object, although the physical structure of the terrycloth object could support copulatory behavior and although, in the absence of a blocking stimulus, the terrycloth object became conditioned faster than did the wood block. However, blocking did not occur when a taxidermically prepared female quail head was added to the terrycloth object. Responding to the terrycloth + head object was primarily a result of associative processes (Experiment $3 \mathrm{~A}$ ), but the presence of a conditioned audiovisual cue did not block conditioning of the terrycloth + head stimulus (Experiment 3B).

The observation of different degrees of blocking depending on the nature of the added stimulus is consistent with previous findings in more conventional conditioning preparations (see, e.g., Feldman, 1975; LoLordo et al., 1982). Such findings have important implications for the mechanisms of blocking. According to associative tradeoff explanations of blocking (see, e.g., Rescorla \& Wagner, 1972), the preconditioning of CS1 to asymptote should block the establishment of an association between CS2 and the US regardless of the nature of CS2, as long as the US is kept constant. The attenuation of blocking as a function of the nature of CS2 suggests the operation of other processes.

The absence of blocking when CS2 contained quail head cues may have reflected facilitated performance of approach behavior in response to the terrycloth + head object or facilitated learning about this stimulus object. Several different mechanisms may have been responsible for facilitated performance of approach behavior to the terrycloth + head object. The results of the first conditioning trial in Experiment 3A indicated that female head cues do not elicit observable approach behavior unconditionally. However, such stimuli may elicit an approach tendency that is below threshold for activating behavior, and this subthreshold approach tendency could summate with low (and possibly behaviorally silent) levels of conditioned excitation to elicit substantial approach responding. Summation of subthreshold response tendencies can account for some approach behavior but cannot readily explain why the blocking group showed as vigorous responding in Experiment 3B as did the control groups, which presumably acquired more conditioned excitation to the terrycloth + head object.

Another explanation that is focused on performance factors attributes blocking to a generalization decrement from the conditioning of the CS1-CS2 compound stimulus to the testing of CS2 alone (Pearce, 1987). The more salient CS2 is, the more similar the presentation of CS2 alone will be to the CS1-CS2 compound. Therefore, more conditioned responding (and hence less blocking) will be evident with more salient added stimuli. The terrycloth + head object presented alone in Experiment 3B may have been more similar to the CS1-CS2 compound than were the added stimuli used in Experiments 1 and 2.

A third variant of a performance account of the failure of blocking of responding to the terrycloth + head object may be constructed from the observation that responding to species-typical stimuli can be enhanced by condi- 
tioned stimuli (see Domjan, 1992, for a review). For the blocking group in Experiment $3 \mathrm{~B}$, access to a receptive female during Phase 1 of the experiment was provided by opening a vertically sliding door. Thus, the vertical movement of the door was consistently paired with access to the female. Presentation of the terrycloth + head object also involved cues of vertical movement, in this case vertical movement of the hood that covered the CS2 object between trials. Excitation conditioned to the vertically sliding door may have generalized to the vertical movement of the hood that covered CS2. These generalized conditioned stimuli may have lowered the threshold for the activation of approach behavior that may have been unconditionally elicited by the shape and plumage of a female quail's head (cf. Domjan et al., 1989).

The absence of blocking when CS2 contained quail head cues also may have reflected facilitated conditioning of the terrycloth + head object. The terrycloth + head object may have disrupted responding to the preconditioned audiovisual cue more than did the wood block and terryclothonly objects used in Experiments 1 and 2. Greater disruption of responding to the preconditioned audiovisual cue may reduce the blocking effect of the preconditioned cue and result in stronger conditioning of the added stimulus (cf. Kamin, 1969). Another possibility is that more salient CSs, or CS objects that contain species-typical features, are more likely to attract attention and therefore are more likely to generate the kind of rehearsal that is necessary for the formation of associations (cf. LoLordo et al., 1982). Finally, blocking may not have occurred with the terrycloth + head object because this object was more similar to the unconditioned stimulus-access to a live female quail-than were the added stimuli used in Experiments 1 and 2 . Similarity has been found to facilitate the formation of associations in second-order conditioning (see, e.g., Rescorla \& Furrow, 1977) and may also facilitate first-order conditioning (Testa, 1975). Faster acquisition resulting from CS-US similarity may have caused the absence of blocking that was observed in Experiment 3B.

\section{REFERENCES}

BAKER, A. G., \& MACKInTosh, N. J. (1977). Excitatory and inhibitory conditioning following uncorrelated presentations of CS and UCS. Animal Learning \& Behavior, 5, 315-319.

CARR, F. A. (1974). Latent inhibition and overshadowing in conditioned emotional response conditioning with rats. Journal of Comparative \& Physiological Psychology, 68, 718-723.

Crawford, L. L., \& AKINS, C. K. (1993). Stimulus control of copulatory behavior in male Japanese quail. Poultry Science, 72, 722-727.

Crawford, L. L., \& Domjan, M. (1993). Sexual approach conditioning: Omission contingency tests. Animal Learning \& Behavior, 21, 42-50.

Domjan, M. (1983). Biological constraints on instrumental and classical conditioning: Implications for general process theory. In G. H. Bower (Ed.), The psychology of learning and motivation (Vol. 17, pp. 215277). Orlando, FL: Academic Press

Domjan, M. (1992). Adult learning and mate choice: Possibilities and experimental evidence. American Zoologist, 32, 48-61.
Domjan, M., Greene, P., \& North, N. C. (1989). Contextual conditioning and the control of copulatory behavior by species-specific sign stimuli in male Japanese quail. Journal of Experimental Psychology: Animal Behavior Processes, 15, 147-153.

Domjan, M., Huber-McDonald, M., \& Holloway, K. S. (1992). Conditioning copulatory behavior to an artificial object: Efficacy of stimulus fading. Animal Learning \& Behavior, 20, 350-362.

Domjan, M., Lyons, R., North, N. C., \& Bruell, J. (1986). Sexual Pavlovian conditioned approach behavior in male Japanese quail (Coturnix coturnix japonica). Journal of Comparative Psychology, $100,413-421$.

Domjan, M., \& NaSh, S. (1988). Stimulus control of social behavior in male Japanese quail, Coturnix coturnix japonica. Animal Behaviour, 36, 1006-1015.

Domuan, M., O'Vary, D., \& Greene, P. (1988). Conditioning of appetitive and consummatory behavior in male Japanese quail. Journal of the Experimental Analysis of Behavior, 50, 505-519.

Domjan, M., \& RaverT, R. D. (1991). Discriminating the sex of conspecifics by male Japanese quail (Coturnix coturnix japonica). Journal of Comparative Psychology, 105, 157-164.

Feldman, J. M. (1975). Blocking as a function of added cue intensity. Animal Learning \& Behavior, 3, 98-102.

ForeE, D. D., \& LoLordo, V. M. (1973). Attention in the pigeon: The differential effect of food getting vs. shock avoidance procedures. Journal of Comparative \& Physiological Psychology, 85, 551-558.

Gamzu, E. R., \& Williams, D. R. (1973). Associative factors underlying the pigeon's key pecking in auto-shaping procedures. Journal of the Experimental Analysis of Behavior, 19, 225-232.

Holloway, K. S., \& Domuan, M. (1993). Sexual approach conditioning: Unconditioned stimulus factors. Journal of Experimental Psychology: Animal Behavior Processes, 19, 38-46.

KAMIN, J. K. (1969). Predictability, surprise, attention, and conditioning. In A. B. Campbell \& R. M. Church (Eds.), Punishment and aversive behavior (pp. 279-296). New York: Appleton-Century-Crofts.

LoLordo, V. M., JACOBs, W. J., \& ForeE, D. D. (1982). Failure to block control by a relevant stimulus. Animal Learning \& Behavior, 10, 183-192.

Mackintosh, N. J. (1973). Stimulus selection: Learning to ignore stimuli that predict no change in reinforcement. In R. A. Hinde \& J. Stevenson-Hinde (Eds.), Constraints on learning (pp. 75-100). Orlando, FL: Academic Press.

Matzel, L. D., Schachtman, T. R., \& Miller, R. R. (1988). Learned irrelevance exceeds the sum of CS pre-exposure and US pre-exposure deficits. Journal of Experimental Psychology: Animal Behavior Processes, 14, 311-319.

PeArCe, J. M. (1987). A model for stimulus generalization in Pavlovian conditioning. Psychological Review, 84, 61-73.

Rescorla, R. A. (1971). Variation in the effectiveness of reinforcement and nonreinforcement following prior inhibitory conditioning. Learning \& Motivation, 2, 113-123.

ResCorla, R. A., \& FurRow, D. R. (1977). Stimulus similarity as a determinant of Pavlovian conditioning. Journal of Experimental Psychology: Animal Behavior Processes, 3, 203-215.

Rescorla, R. A., \& Wagner, A. R. (1972). A theory of Pavlovian conditioning: Variations in the effectiveness of reinforcement and nonreinforcement. In A. H. Black \& W. F. Prokasy (Eds.), Classical conditioning II (pp. 64-99). New York: Appleton-Century-Crofts.

Testa, T. J. (1975). Effects of similarity of location and temporal intensity pattern of conditioned suppression in rats. Joumal of Experimental Psychology: Animal Behavior Processes, 1, 114-121.

Tomie, A., Murphy, A. L. , FAth, S., JAckson, R. L. (1980). Retardation of autoshaping following pretraining with unpredictable food. Effects of changing the context between pretraining and testing. Learning \& Motivation, 11, 230-238.

(Manuscript received September 24, 1992; revision accepted for publication September $7,1993$. 